\title{
Erratum to: Psychological and Social Measurement: The Career and Contributions of Benjamin D. Wright
}

\author{
Mark Wilson and William P. Fisher, Jr.
}

Erratum to:

M. Wilson, W.P. Fisher, Jr. (eds.), Psychological and Social

Measurement, Springer Series in Measurement Science and Technology, https://doi.org/10.1007/978-3-319-67304-2

The original version of this book included erroneous affiliations that were inadvertently introduced during the production process. These incorrect affiliations appeared in the Front matter and in Chapters 1, 8, 14 and 15 of the original version.

The correct affiliations are shown below and the book has now been updated to reflect this correction:

\section{Editors}

Mark Wilson

Graduate School of Education

University of California, Berkeley

Berkeley, CA, USA

William P. Fisher, Jr.

Graduate School of Education

University of California, Berkeley

Berkeley, CA, USA

The updated online version of these chapters can be found at https://doi.org/10.1007/978-3-319-67304-2_1

https://doi.org/10.1007/978-3-319-67304-2_8

https://doi.org/10.1007/978-3-319-67304-2_14

https://doi.org/10.1007/978-3-319-67304-2_15

The updated online version of this book can be found at https://doi.org/10.1007/978-3-319-67304-2 